\title{
Quantifying perfusion-related energy losses during magnetic resonance-guided focused ultrasound
}

\author{
Christopher Dillon*, Robert Roemer, Allison Payne \\ From Current and Future Applications of Focused Ultrasound 2014. 4th International Symposium \\ Washington, D.C, USA. 12-16 October 2014
}

\section{Background/introduction}

The focused ultrasound power required for successful ablation of uterine fibroid tissue varies substantially between patients and within single treatments. $[1,2]$ Fibroids with high signal intensity in pretreatment T2-weighted MR images have been shown to require increased power to achieve adequate temperature elevation for ablation; [2,4] thus, T2-weighted signal intensity has been suggested as a predictor of MRgFUS treatment response.[2,3] Physiologically, the high intensity of T2weighted MR images of uterine fibroids may represent vascularization, fluid-rich tissues, or degeneration. $[4,6]$ By quantifying perfusion-related energy losses $(\mathrm{Qb})$ during MRgFUS treatments, this study is the first step in linking perfusion-related energy losses with MR perfusion imaging. This knowledge could be used to improve biothermal modeling of MRgFUS fibroid treatments and as a potential independent predictor of treatment response and outcome.

\section{Methods}

Experiments were performed in ex vivo porcine kidneys perfused with a heparin- $\mathrm{H}_{2} \mathrm{O}$ solution in variable flow $(0$, $20,40 \mathrm{~mL} / \mathrm{min}$ ) situations and embedded in a gelatin phantom (Figure 1). Heating was achieved by electronically steering a phased-array ultrasound transducer $(256$ elements, $\mathrm{f}=1 \mathrm{MHz}$ ) in an $8 \mathrm{~mm}$-radius circle for $120 \mathrm{~s}$ (Figure 2). MR temperature data (Figure 3) were acquired with a 3T Siemens Trio MRI (3D segmented-EPI, TR/ $\mathrm{TE}=30 / 11 \mathrm{~ms}, \mathrm{FA}=15^{\circ}$, EPI factor $=9,2 \times 2 \times 3 \mathrm{~mm} 3,3.3 \mathrm{~s}$ acquisition, ZFI to $0.5-\mathrm{mm}$ isotropic spacing). Based on conservation of energy principles, deviation of a thermal model that excludes perfusion effects from the experimental temperatures was used to quantify $\mathrm{Qb}$. Estimates of $\mathrm{Qb}$ were obtained at the time of each MR acquisition during

University of Utah, Salt Lake City, Utah, United States

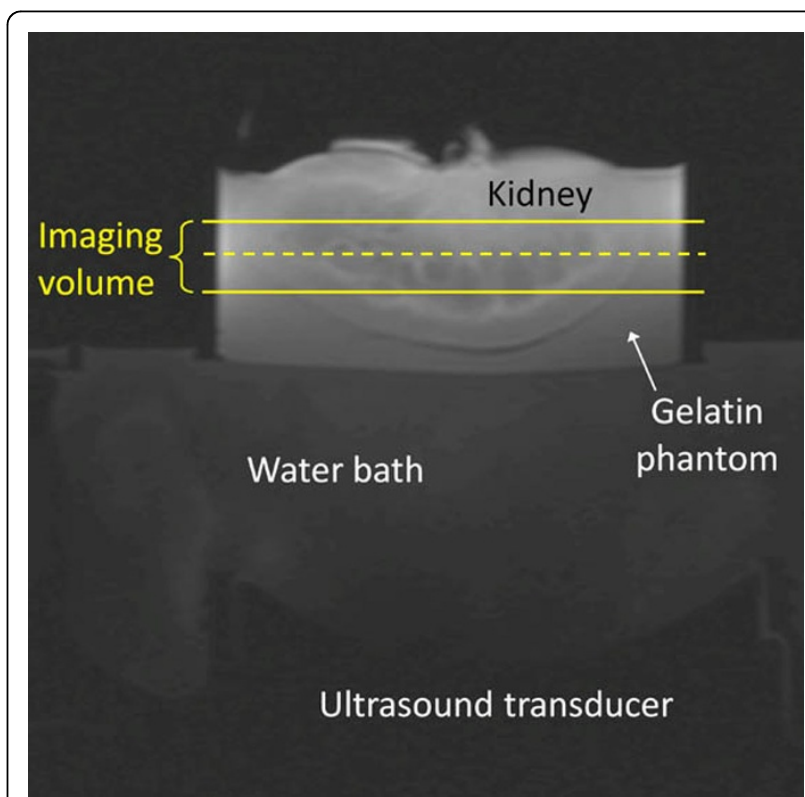

Figure 1 Experimental setup for MRgFUS heating of ex vivo perfused porcine kidney embedded in a gelatin phantom. Solid lines indicate the 3D MR temperature imaging volume and the dashed line indicates the location of the coronal magnitude image seen in figure 2.

cooling, transformed into perfusion values via the Pennes bioheat transfer equation,[7] and averaged to mitigate the effects of noise.

\section{Results and conclusions}

High perfusion values (Figure 4) correspond to regions of increased cooling (Figure 3) and likely indicate locations of discrete vasculature. Constant, uniform perfusion values ranged from $-0.7-0.1,1.6-3.9$, and $3.4-4.4$ $\mathrm{kg} / \mathrm{m} 3 / \mathrm{s}$ for 0,20 , and $40 \mathrm{~mL} / \mathrm{min}$ flow rates, respectively, following anticipated trends with perfusion approximately zero for the no flow case and increasing 


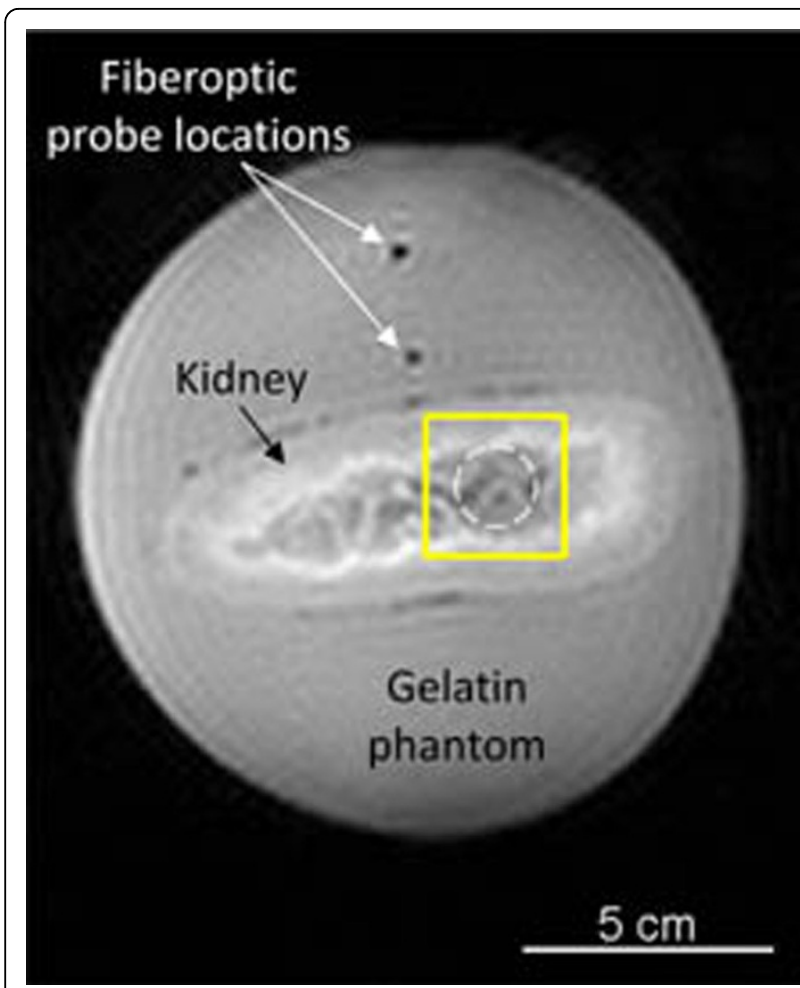

Figure 2 Coronal magnitude image obtained during MRgFUS heating. Fiberoptic probes measured the background temperature. The dashed line indicates the circular heating region and the solid line identifies the region of interest for data presented in figures 3 and 4 .

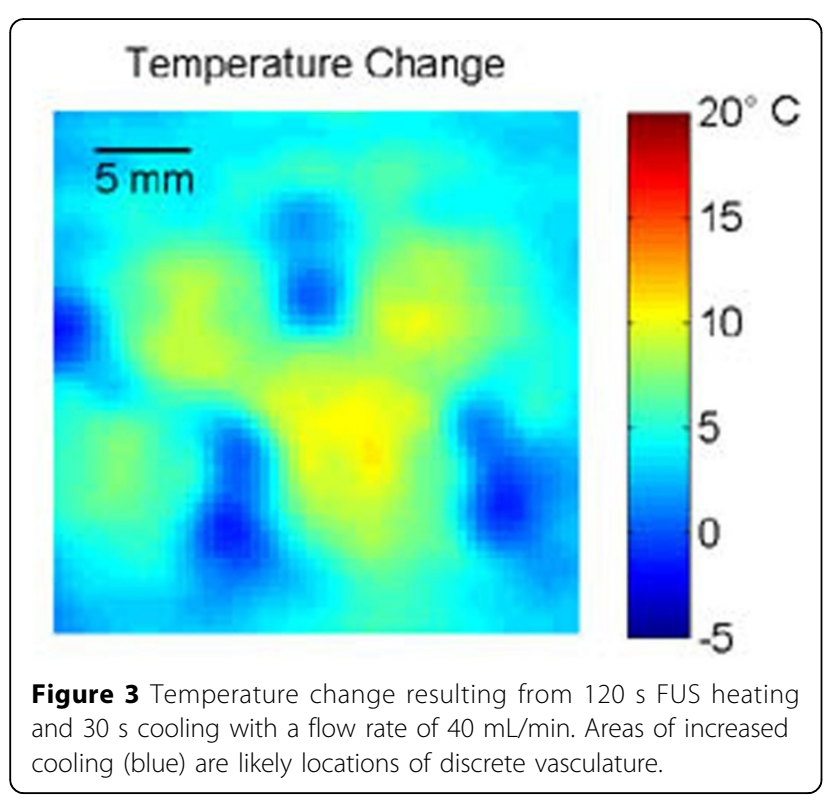

with flow rate. Future work will relate MR perfusion imaging to Qb, which should eliminate the need for tissue heating for improved biothermal modeling. This study demonstrates that obtaining perfusion estimates

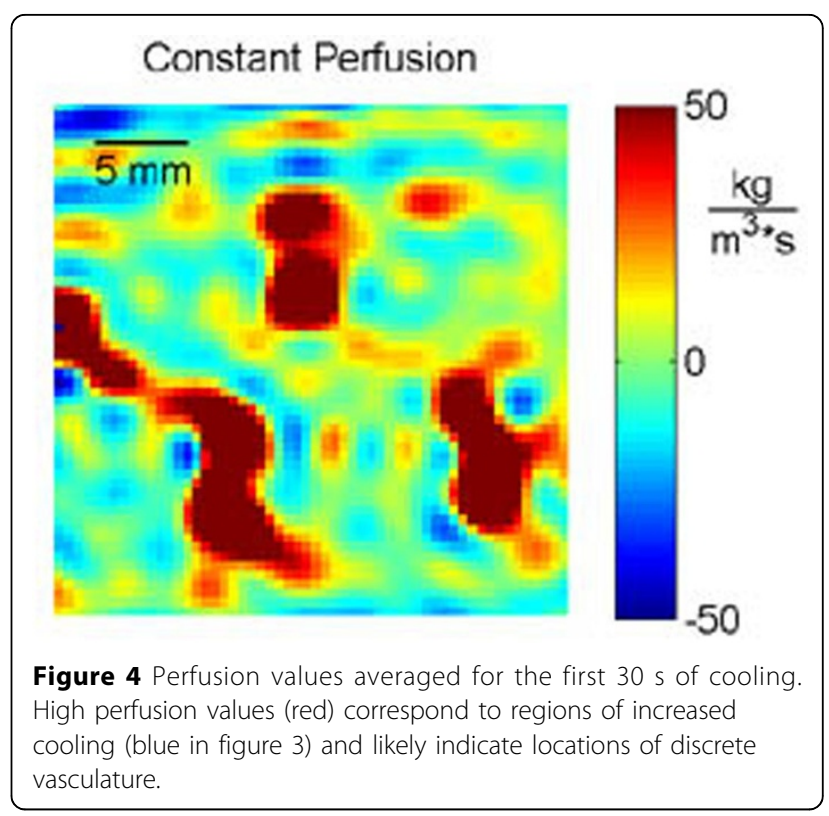

from 3D MR temperature data during MRgFUS is feasible and has the potential to improve biothermal models of MRgFUS fibroid treatments.

\section{Acknowledgements (Funding)}

This work was funded by Siemens Healthcare AG, the FUS Foundation, the Ben and Iris Margolis Foundation, and by NIH grants R01 CA87785 and R01 EB013433.

\section{Published: 30 June 2015}

\section{References}

1. McDannold N, et al: Uterine Leiomymomas: MR Imaging-based Thermometry and Thermal Dosimetry during Focused Ultrasound Thermal Ablation. Radiology 2006, 240(1):263-272.

2. Lenard Z, et al: Uterine Leiomyomas: MR Imaging-guided Focused Ultrasound Surgery-Imaging Predictors of Success. Radiology 2008 249(1):187-194.

3. Funaki, et al: Magnetic resonance-guided focused ultrasound surgery for uterine firboids: relationship between the therapeutic effects and signal intensity of preexcisting T2-weighted magnetic resonance images. Am J Obstet Gynecol 2007, 196(2):e1-6.

4. Fennessy F, Tempany C: An Update on Magnetic Resonance Guided Focused Ultrasound Surgery (MRgFUS) of Uterine Fibroids. Curr Radiol Rep 2013, 1(2)

5. Swe Radiat Med 1992

6. Oguchi $\mathrm{O}$, et al: Prediction of histopathologic features and proliferative activity of uterine leiomyoma by magnetic resonance imaging prior to $\mathrm{GnRH}$ analogue therapy: correlation between T2-weighted images and effect of GnRH analogue. J Obstet Gynaecol 1995, 21(2):107-17.

7. Pennes $\mathrm{H}$ : Analysis of tissue and arterial blood temperature in the resting human forearm. J Appl Physiol 1978, 1:93-122.

doi:10.1186/2050-5736-3-S1-0103

Cite this article as: Dillon et al:: Quantifying perfusion-related energy losses during magnetic resonance-guided focused ultrasound. Journal of Therapeutic Ultrasound 2015 3(Suppl 1):0103. 